\title{
Effects of a newly invasive parasite on the burrowing mud shrimp, a widespread ecosystem engineer
}

\author{
Blaine D. Griffen* \\ Department of Biological Sciences and Marine Science Program, University of South Carolina, Columbia, \\ South Carolina 29208, USA
}

\begin{abstract}
The burrowing mud shrimp Upogebia pugettensis is an important ecosystem engineer in Pacific bays and estuaries from Alaska to Baja California. Recently, mud shrimp populations throughout this range have declined precipitously. This decline has followed invasion by a bopyrid isopod, Orthione griffenis, which parasitizes and removes hemolymph from the shrimp's gill chambers. However, a causal link between this invasive parasite and the decline of its host has yet to be demonstrated. I used observed allometric relationships between the parasite and its host, spatial patterns of parasite prevalence across host demographics, and simulation modeling to explore potential mechanisms leading to this causal link. Results here, considered with other work, suggest that this parasite may hamper host reproduction by increasing metabolic demands. First, shrimp are more likely to become infected with increasing exposure to parasite-laden water, which varies both with the proportion of time that tides cover individual shrimp burrows and with each shrimp's size-specific pumping rate of water through its burrow. Second, parasites impose a metabolic burden on their host that is proportional to parasite size, which itself increases with time since infection. Third, increasing metabolic costs in turn reduce reproductive capacity, potentially through feminization of male hosts. Fourth, increased metabolic costs of infection are most detrimental when feeding time is limited, which occurs in higher intertidal areas. These conclusions should be taken as testable hypotheses that, if examined, will elucidate this host-parasite interaction and clarify if this new invasive parasite is capable of reducing and eliminating this important ecosystem engineer.
\end{abstract}

KEY WORDS: Bopyrid isopod · Feminization · Orthione griffenis Parasite $\cdot$ Upogebia pugettensis

\section{INTRODUCTION}

Parasites are an abundant and important component of ecological systems (Hudson 2005), yet are less understood in many respects than other components, such as predators or competitors. By definition, parasites reduce host fitness. However, the strength of these impacts - the magnitude of the effect on individual host fitness - varies widely. Some parasites cause rapid host mortality (e.g. Granath \& Esch 1983, Jaenike et al. 1995), others reduce host fecundity (e.g. Saumier et al. 1986, Brown et al. 1994), and others have effects that are only weakly detectable (e.g. Mitchell 1984, Munger \& Karasov 1989).

Invasive parasites may have particularly large impacts because hosts have not evolved with the para- site and therefore have not acquired the ability to cope with parasite infection (Day 1981). For example, the Asian cyprinid Pseudorasbora parva that was recently introduced to European waters carried with it an intracellular eukaryotic parasite that has subsequently jumped to native European cyprinids (Gozlan et al. 2005). The result is reproductive failure and large population declines of native cyprinids. Similar examples occur in plant systems. Chestnut blight Cryphonectria parasitica is a parasitic fungus that invaded North America around the turn of the 20th century. It spread quickly, killing its host and eliminating what was once a dominant species in North American forests (Anagnostakis 1987). A similar example of a detrimental invasive parasite may now be occurring in bays and estuaries along the North American Pacific coast. 
The burrowing mud shrimp Upogebia pugettensis (Dana 1852) has historically been an abundant infaunal organism in bays and estuaries ranging from southern Alaska to Baja California (Mexico). The shrimp establishes U- or Y-shaped burrows in intertidal mudflats where it filters water from the overlying water column. Burrowing and filtering activities of this ecosystem engineer can have substantial ecosystem impacts such as altering benthic community composition (Brenchley 1981, Posey et al. 1991, Dumbauld et al. 2001), altering benthic structure through bioturbation, influencing nitrogen cycling, organic matter remineralization, solute fluxes across the sediment-water interface (DeWitt et al. 2004), and filtering large portions of suspended particles from the water column (Griffen et al. 2004).

Thalassinids and caridean shrimp are often infected by bopyrid isopods (Markham 1985), most of which lodge themselves in the gill chamber under the carapace and subsequently feed off the hosts' blood. Parasites in crustaceans, including bopyrid isopods, are capable of eliminating host reproduction, either through castration (Kuris 1974, O'Brien \& Van Wyk 1985) or feminization of males (e.g. Ironside et al. 2003). Upogebia pugettensis is infected by Phyllodurus abdominalis, a native bopyrid that attaches to the host pleopods with seemingly little impact to the host population due to low prevalence. Recently, a second bopyrid, Orthione griffenis (Markham 2004), invaded the system and attaches itself within the gill chamber of the host throughout most of its range (Dumbauld \& Chapman 2008). Coinciding with the arrival of this new parasite has been a rapid decline in density of $U$. pugettensis observed throughout most of its range. Although O. griffenis apparently only recently invaded, it is now widespread and highly prevalent throughout eastern Pacific shrimp populations and may be responsible for the broad decline of $U$. pugettensis, though a causal mechanism has not yet been demonstrated.

Given the central role of Upogebia pugettensis in estuarine ecosystem processes in areas where it is abundant, the impacts of its decline could be far reaching, underscoring the importance of discovering the causal mechanism. Negative impacts of other bopyrids on host reproduction suggest that Orthione griffenis could potentially have similar impacts on $U$. pugettensis. This would also be consistent with ecological theory, as parasites that strongly decrease host fecundity are predicted to strongly impact host population dynamics, potentially even regulating host populations (Anderson \& May 1978, May \& Anderson 1978, reviewed in Møller 2005). Yet such effects of $O$. griffenis have yet to be detected.

Smith et al. (2008) recently examined the population structure of Upogebia pugettensis and Orthione griffenis and the energetic burden of the parasite on individual hosts at a single site in Yaquina Bay estuary, OR, and came to several conclusions. First, there is a shift in the female:male sex ratio of shrimp with shrimp size, so that the sex ratio is male-biased when shrimp are small and female-biased when shrimp are large. Second, parasite prevalence is higher in female than in male shrimp, and this difference increases with host size. Smith et al. (2008) attributed this to differential survival of hosts or parasites, but also cite an unpublished source suggesting that $O$. griffenis does not influence host survival. Third, parasite burden reduces host weight, and this effect increases with parasite size, but does not seem to differ between male and female hosts. Fourth, they found no evidence that O. griffenis feminizes infected male hosts. Fifth, host size and parasite size were poorly correlated in their study, and thus the size at which hosts generally become infected is obscure, thought it is apparent that very small shrimp are not infected.

Setting aside for a moment the statements by Smith et al. (2008) that Orthione griffenis does not influence host survival or feminize male hosts, there are several mechanisms, or combinations of mechanisms, that could feasibly give rise to the observed patterns in both shrimp sex ratio and parasite prevalence. These mechanisms include higher rates of background (i.e. parasite-independent) mortality, infection-induced mortality, and parasite mortality in male than in female shrimp, higher infection rates in female than in male shrimp, and feminization of infected males so that some observed infected 'females' are misidentified and are actually feminized males. Understanding the mechanisms underlying the observed demographic and prevalence patterns, as well as understanding the size at which shrimp generally become infected, are fundamental to understanding the effects of O. griffenis on Upogebia pugettensis.

Here I present data on Upogebia pugettensis and Orthione griffenis population structures similar to that presented by Smith et al. (2008). However, the data set I present differs in that it was collected from several locations throughout the same estuary (rather than from a single site), as well as from several tidal heights (rather than from a single tidal height). Spatially dispersing sampling effort, especially across tidal heights, provided information that sheds new light on this invasive parasite. I also present results of simulation models used to explore the ability of the mechanisms listed in the preceding paragraph to recreate the observed trends in parasite prevalence and shrimp demographics reported here and by Smith et al. (2008) within Yaquina Bay. Mechanisms that are capable of reproducing these observed trends in model simulations are feasible mechanisms at work in this host-parasite system.

The goals of the present study were to (1) compare the prevalence of parasites in 2001 (present study) to the 
prevalence in the exact same location in 2005 (Smith et al. 2008) to determine whether prevalence increased during that time period (given the recent discovery of Orthione griffenis in Yaquina Bay in 1999 and its very high prevalence by 2005, we may expect that its prevalence was increasing during this period); (2) compare prevalence at different vertical and horizontal locations within the estuary to determine the spatial distribution of O. griffenis; (3) determine whether a size relationship exists between individually infected hosts and their parasites, and to use this relationship to estimate the size at which most hosts are infected; (4) explore potential mechanisms of host-parasite interactions by comparing patterns generated by model simulations with observed field patterns of parasite prevalence across host demographics; and (5) use the data and simulation models presented here to make testable predictions about the effects of $O$. griffenis on its shrimp host.

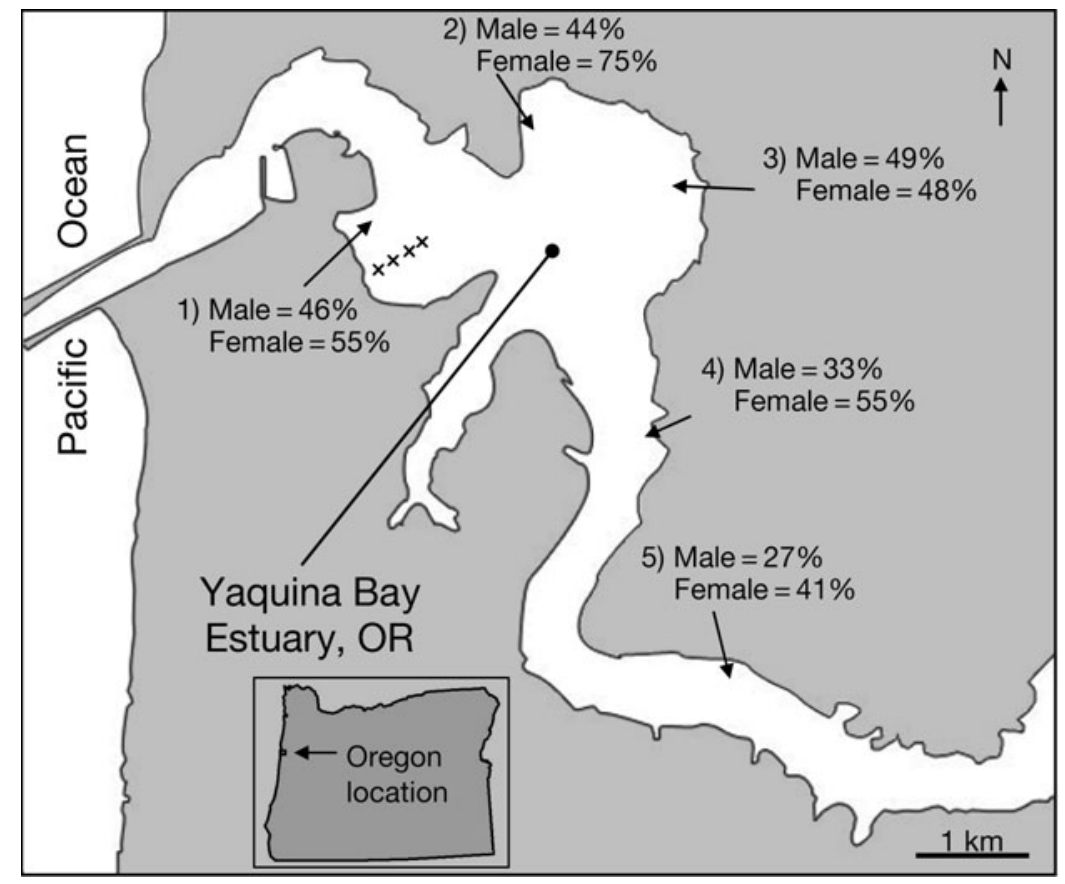

Fig. 1. Yaquina Bay estuary, OR, (estuary mouth at $44^{\circ} 36^{\prime} 49^{\prime \prime} \mathrm{N}, 124^{\circ} 04^{\prime} 19^{\prime \prime} \mathrm{W}$ ) showing sampling locations and prevalence (\%) of the parasite Orthione griffenis infecting male and female Upogebia pugettensis at each sampling location. $x \times x \times$ : location and direction of intertidal transect to examine how prevalence varies with tidal height

\section{MATERIALS AND METHODS}

Sampling. I determined how parasite prevalence varies throughout Yaquina Bay by sampling shrimp at 5 locations ranging from 3 to $10 \mathrm{~km}$ from the mouth of the estuary in July 2001 (Fig. 1). Locations were chosen based on accessibility and to obtain samples throughout the range of the host's distribution within the estuary. At each of the 5 locations, I sampled 100 shrimp randomly from $0.4 \mathrm{~m}$ above mean low water using a yabby pump (a piston-like suction device that extracts shrimp from their burrows). In addition, I determined how parasite prevalence varies with tidal height by sampling along a single transect that spanned an elevational gradient across an intertidal mud flat from 0.3 to $1.2 \mathrm{~m}$ above mean low water (Fig. 1). At each of 7 tidal heights along the transect, I sampled 20 shrimp that were each $\geq 20 \mathrm{~mm}$ carapace length (CL). Tidal heights were approximated using a NOAA tide chart for the site.

For each shrimp I determined sex, CL (from the tip of the rostrum to the back edge of the carapace), presence/absence of Orthione griffenis, and the wet weight of parasites. I determined the prevalence of the parasite by dividing the number of infected shrimp by the total number sampled at each site or at each tidal height. Shrimp were determined to be females based on the presence of a modified first pleopod (Dumbauld et al. 1996, Smith et al. 2008). However, I did not examine either the presence of gonopores or the size of chelipeds, both of which can also be used to determine shrimp sex and the occurrence of feminization (Tucker 1930, Beck 1980, Smith et al. 2008). Thus if parasiteinduced feminization of hosts occurs, then 'males' reported here are truly males, while infected 'females' may be either females or feminized males (I discuss the implications of this potential misidentification of gender below).

I determined how parasite prevalence varied with shrimp CL, shrimp sex, and site using logistic regression (GAM from the mgcv package in $\mathrm{R}$ v2.7.1, with family = binomial) with shrimp CL treated as a continuous variable and sex and site treated as factors. For this analysis, I initially included site as a factor in the analysis. However, there was no effect of site on parasite prevalence and I therefore pooled the data across all 5 sites for the final analysis. I determined how parasite prevalence varied with tidal height and shrimp sex using logistic regression with data from the transect (GAM, family = binomial; shrimp CL was not included in this analysis because only large shrimp were sampled during transect sampling). Finally, using infected shrimp from all 5 sites and from the transect, I examined how parasite wet weight varied with shrimp CL 
and sex using analysis of covariance (ANCOVA), with sex treated as a factor and shrimp CL as a covariate. Orthione griffenis are hermaphrodites; the first individual to settle becomes the female and subsequent settlers become male. Because the first parasite to infect the host becomes female, and because there is a large size disparity between male and female O. griffenis, I used only female parasites when both male and female were present. Visual inspection of plots of parasite wet weight vs. shrimp CL indicated 2 different clusters of data points: one for female parasites $>100 \mathrm{mg}$ and one for female parasites <100 mg, each with apparently different slopes. These 2 groups were therefore analyzed with separate ANCOVAs.

Simulation models. I used a series of 6 individualbased, stochastic simulation models to explore the ability of several potential mechanisms to reproduce the observed patterns of changing parasite prevalence and shrimp sex ratio with shrimp size described above. These patterns were observed both in the data reported here and by Smith et al. (2008). Simulation models were designed specifically to test hypotheses proposed by Smith et al. (2008) and to test alternative hypotheses proposed here. As such, they are, admittedly, simplifications and include the following assumptions.

Both Upogebia pugettensis and Orthione griffenis have complex life histories with pelagic larvae (reviewed for $U$. pugettensis in Dumbauld et al. 1996, and for O. griffenis in Smith et al. 2008). I therefore first assumed that both host and parasite populations are open and that recruits for both species originated from outside the local populations. Thus the model simulations here do not include density-dependent feedbacks to infection rates that often characterize host-parasite interactions. Second, I assumed that shrimp reach $10 \mathrm{~mm}$ CL by 1 yr of age and grow at a constant rate of $5 \mathrm{~mm} \mathrm{CL} \mathrm{yr}^{-1}$ thereafter, becoming mature at approximately $20 \mathrm{~mm}$ CL (Dumbauld et al. 1996). The time step in the models was therefore $1 \mathrm{yr}$, with shrimp $\geq 1 \mathrm{yr}$ of age increasing in size by $5 \mathrm{~mm}$ from one time step to the next. This is clearly a simplification, as growth rate is likely influenced by submergence time (i.e. feeding time) and thus tidal height. However, data were unavailable to determine the relationship between tidal height, shrimp age, and shrimp growth rate. I therefore did not include tidal height explicitly in these models, but used results of tidal height sampling only to shed light on model results. Third, I assumed that shrimp could not be infected until CL > $10 \mathrm{~mm}$, consistent with results of sampling presented here and in Smith et al. (2008). Fourth, I assumed that parasite size, and thus the burden placed upon its host, increases with the duration of time since infection (Smith et al. 2008).

Parasite prevalence increases with shrimp size (see 'Results', Smith et al. 2008). This pattern could arise if shrimp experience a constant probability of infection through time, as large individuals would simply have been exposed to the risk longer than small individuals. Alternatively, infection rate may be proportional to size-specific exposure rates. Orthione griffenis infects a primary zooplankton host in open coastal waters (microniscus stage) before returning to intertidal areas as a cryptoniscan to infect the final shrimp host. Shrimp can thus only become infected upon exposure to water carrying the cryptoniscan parasite stage. The burrowing lifestyle of shrimp suggests that they may become exposed to parasites as they pump water through their burrow. The rate of infection for shrimp may therefore be proportional to their size-specific pumping rates (Griffen et al. 2004). I developed a preliminary model in which I compared these 2 modes of infection (constant and size-specific probability) to determine whether either could produce the range in parasite prevalence observed with shrimp size. Only infection as a function of shrimp pumping rate reproduced the observed range of prevalence with shrimp size. I therefore assumed this mechanism in all subsequent models.

I first developed a null model in which mortality rate of infected and healthy shrimp were constant, in which no parasite mortality occurred (i.e. parasites remained with the host until host death), in which infection rates were the same for male and female shrimp and no feminization occurred. I then modified this null model in various ways for each of the subsequent models to explore 5 different potential mechanisms: (1) higher background mortality in male than in female shrimp, (2) higher infection-induced mortality in male than in female hosts, (3) higher infection rate in female than in male shrimp, (4) mortality of parasites in male hosts, and (5) feminization of male hosts. Table 1 describes differences in each of the 6 models.

Except for differences described in Table 1, each model was identical and was initiated with 2500 newly settled shrimp with the sex of each randomly decided. At each yearly time step, the models then performed the following steps. First, the size of all shrimp in the population increased by $5 \mathrm{~mm}$ (except for $1 \mathrm{yr}$ old shrimp, whose size increased to $10 \mathrm{~mm}$ ). Next, the model cycled through each member of the population individually and performed the following tasks for each individual:

(1) The model randomly decided whether individuals that were $>10 \mathrm{~mm}$ CL became infected, with the probability of infection varying proportionally to sizespecific pumping rates.

(2) The model randomly decided whether an individual lived or died, with the probability of death varying depending on the model.

(3) The model randomly determined whether parasites lived or died (Model 5 only, Table 1). Hosts whose 
Table 1. Model simulations used to examine potential mechanisms that explain observed patterns of host-parasite demographics in Yaquina Bay estuary, Oregon. M, F: male and female shrimp, respectively; inf., uninf.: infected and uninfected shrimp, respectively; $P$ : shrimp size-specific pumping rate of water through burrow $\left(P=0.62 \times\right.$ dry weight $^{0.58}$; Griffen et al. 2004); Prob $_{\text {femin: }}$ probability of feminization of infected mature male shrimp

\begin{tabular}{|c|c|c|c|c|}
\hline Model & $\begin{array}{l}\text { Shrimp mortality } \\
\text { (annual, \%) }\end{array}$ & Infection rate & $\begin{array}{l}\text { Parasite mortality } \\
(\%)\end{array}$ & $\operatorname{Prob}_{\mathrm{femin}}$ \\
\hline 1 (null model) & $\begin{array}{l}\text { F: } 50 \\
\text { M: } 50\end{array}$ & Proportional to $P$ & 0 & 0 \\
\hline 2 & $\begin{array}{l}\text { F: } 50 \\
\text { M: } 70\end{array}$ & Proportional to $P$ & 0 & 0 \\
\hline 3 & $\begin{array}{l}\text { F: } 50 \\
M \text { (uninf.): } 50 \\
M \text { (inf. >1 yr): } 90\end{array}$ & Proportional to $P$ & 0 & 0 \\
\hline 4 & $\begin{array}{l}\text { F: } 50 \\
\text { M: } 50\end{array}$ & $\begin{array}{l}\text { F: Proportional to } P \\
\text { M: } 0.4 \times \text { F rate }\end{array}$ & 0 & 0 \\
\hline 5 & $\begin{array}{l}\mathrm{F}: 50 \\
\mathrm{M}: 50\end{array}$ & Proportional to $P$ & $\begin{array}{l}\text { F: } 0 \\
M(\text { inf. } \leq 1 \mathrm{yr}): 0 \\
M(\text { inf. }>1 \text { yr): } 70\end{array}$ & 0 \\
\hline 6 & $\begin{array}{l}\mathrm{F}: 50 \\
\mathrm{M}: 50\end{array}$ & Proportional to $P$ & 0 & $\begin{array}{l}\text { Newly inf.: } 0.5 \\
\text { increasing to } 0.95 \\
\text { after inf. } \geq 2 \mathrm{yr}\end{array}$ \\
\hline
\end{tabular}

parasite died remained in the population and were treated identically to all other uninfected shrimp.

(4) Infected male hosts were feminized. Feminization was only permitted among mature hosts ( $\geq 20 \mathrm{~mm})$, and the probability of feminization increased with parasite size (i.e. with time since infection, Model 6 only, Table 1). The model subsequently treated all feminized individuals as females.

(5) Finally, 2500 new shrimp recruits were added to the population, with the sex of each shrimp randomly decided. (The starting population size and number of new recruits per time step were chosen based on preliminary model simulations and reflect sufficient numbers to provide the desired resolution in model results, while simultaneously limiting the number of simulated individuals in an effort to reduce model run-time.)

Each model was iterated for 10 time steps, which preliminary trials indicated was sufficient to establish an approximate steady state in parasite prevalence and shrimp sex ratio. Model simulations were performed using R v2.7.1.

Three metrics were obtained as output from each model: (1) frequency of females in the population (i.e. no. females/total no. shrimp); (2) prevalence of infection among females (i.e. no. infected females/total no. females); and (3) prevalence of infection among males (i.e. no. infected males/total no. males). These 3 metrics were obtained for each of 6 size classes of individuals: $\leq 1,2,3,4,5$, and $6 \mathrm{yr}$ of age $(\leq 10,15,20,25,30$, and $35 \mathrm{~mm} \mathrm{CL}$, respectively). These age classes were derived from linear growth models given by Dumbauld et al. (1996) and represent age approximations rather than precise age-size relationships. Each model was replicated 100 times and the mean and SD of each of these 3 metrics was obtained for each model. I then compared these metrics to the same metrics in the population within Yaquina Bay to determine which of the mechanisms listed in Table 1 were capable of reproducing observed patterns. In addition to the mortality, infection, and feminization rates given in Table 1, which are the values that most closely reproduced the observed patterns, I also varied these rates over a wide range (host and parasite mortality: 5 to $95 \%$ annually; infection: 5 to $75 \%$ annually; feminization of infected males: 5 to $100 \%$ annually) to test model sensitivity.

\section{RESULTS}

\section{Sampling}

Overall, parasite prevalence increased with shrimp CL (GAM, $z=4.81, p<0.0001)$. However, this increase was monotonic for female shrimp, whereas parasite prevalence in males increased up to $20 \mathrm{~mm}$ host CL and then remained fairly constant (Fig. 2A). While parasite prevalence differed between sites (Fig. 1), these differences were not significant $(p>0.05)$ and site was not included in the final analysis. As shrimp CL increased there was a general increase in the proportion of shrimp (infected and uninfected) that were identified as female (Fig. 2A). 

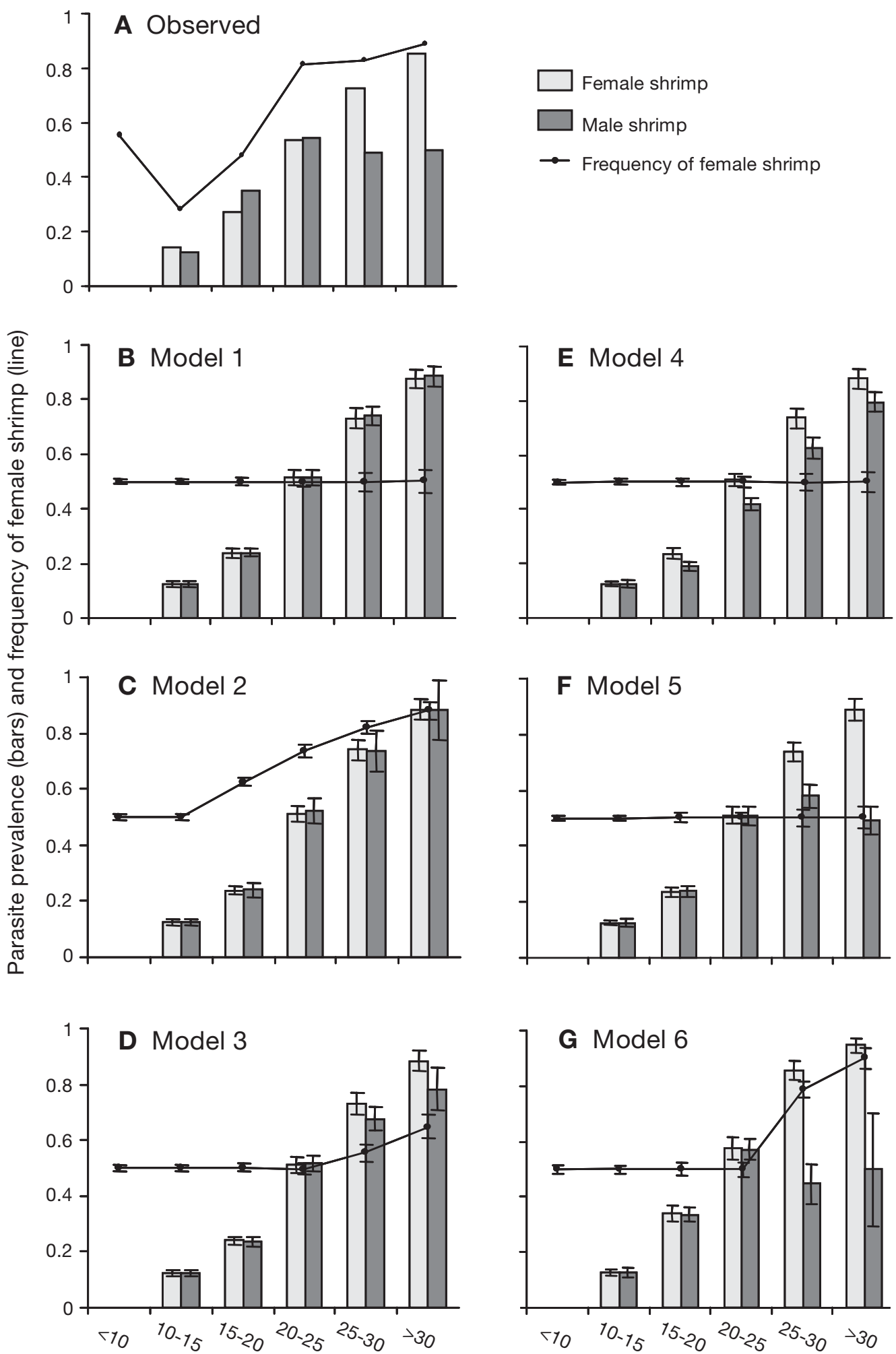

Shrimp CL $(\mathrm{mm})$

Fig. 2. Orthione griffenis and Upogebia pugettensis. (A) Observed prevalence of $O$. griffenis in male and female $U$. pugettensis of different sizes, and the proportion of the shrimp population identified as female for each size class. (B-G) Model-predicted prevalence of $O$. griffenis in male and female shrimp of different sizes, and the proportion of the shrimp population that are female (including feminized males) in each size class. Differences between these models are described in Table 1. CL: carapace length 
Parasite prevalence was inversely related to intertidal height along the transect (GAM, $z=-2.88, \mathrm{p}=$ $0.004)$. However, this trend was only observed for male shrimp; parasite prevalence among female shrimp remained fairly constant with tidal height (GAM, tidal height $\times$ sex interaction, $z=-2.29, p=0.02$, Fig. 3A). Within this single transect, there was also a change in the male:female ratio with tidal height, with approximately equal numbers of males and females at high and low tidal heights, but many more females than males at intermediate tidal heights (Fig. 3B).

No parasites were observed in either male or female shrimp $<12 \mathrm{~mm}$ CL. There was a general increase in parasite size with increasing shrimp CL for both male and female shrimp, and this was the case for both small ( $\leq 100 \mathrm{mg}$ ) and large (>100 mg) female parasites, which were analyzed separately. However, there was a $>30$ fold difference in the slope of this relationship for small and large parasites. Specifically, for small parasites, parasite mass increased by $1.23 \pm 0.55 \mathrm{mg}$ for every $\mathrm{mm}$ increase in shrimp CL (covariate in ANCOVA, $F_{3,168}=6.71, p=0.04 ;$ Fig. 4), regardless of shrimp sex (main effect in ANCOVA, $\mathrm{p}=0.34$, shrimp sex $\times \mathrm{CL}$ interaction term $\mathrm{p}=0.16$ ); whereas for large parasites,
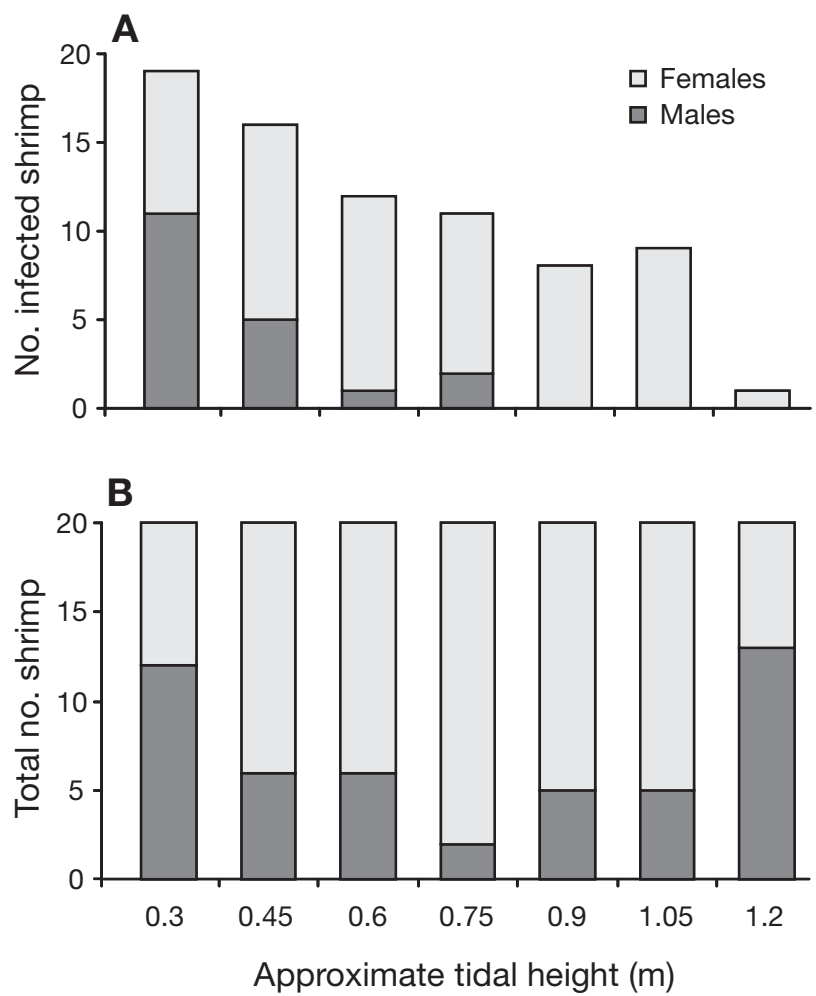

Fig. 3. Orthione griffenis and Upogebia pugettensis. (A) Change in prevalence of $O$. griffenis infecting large $(>20 \mathrm{~mm}$ $\mathrm{CL}$ ) male and female $U$. pugettensis with tidal height. (B) Contribution of shrimp identified as males and females to the total sample at each tidal height parasite mass increased by $37.77 \pm 5.06 \mathrm{mg}$ for every $\mathrm{mm}$ increase in shrimp CL (covariate in ANCOVA, $F_{3,148}=24.35, p \ll 0.001$; Fig. 4), regardless of shrimp sex (main effect in ANCOVA, $p=0.30$, shrimp sex $\times$ CL interaction term, $\mathrm{p}=0.25$ ).
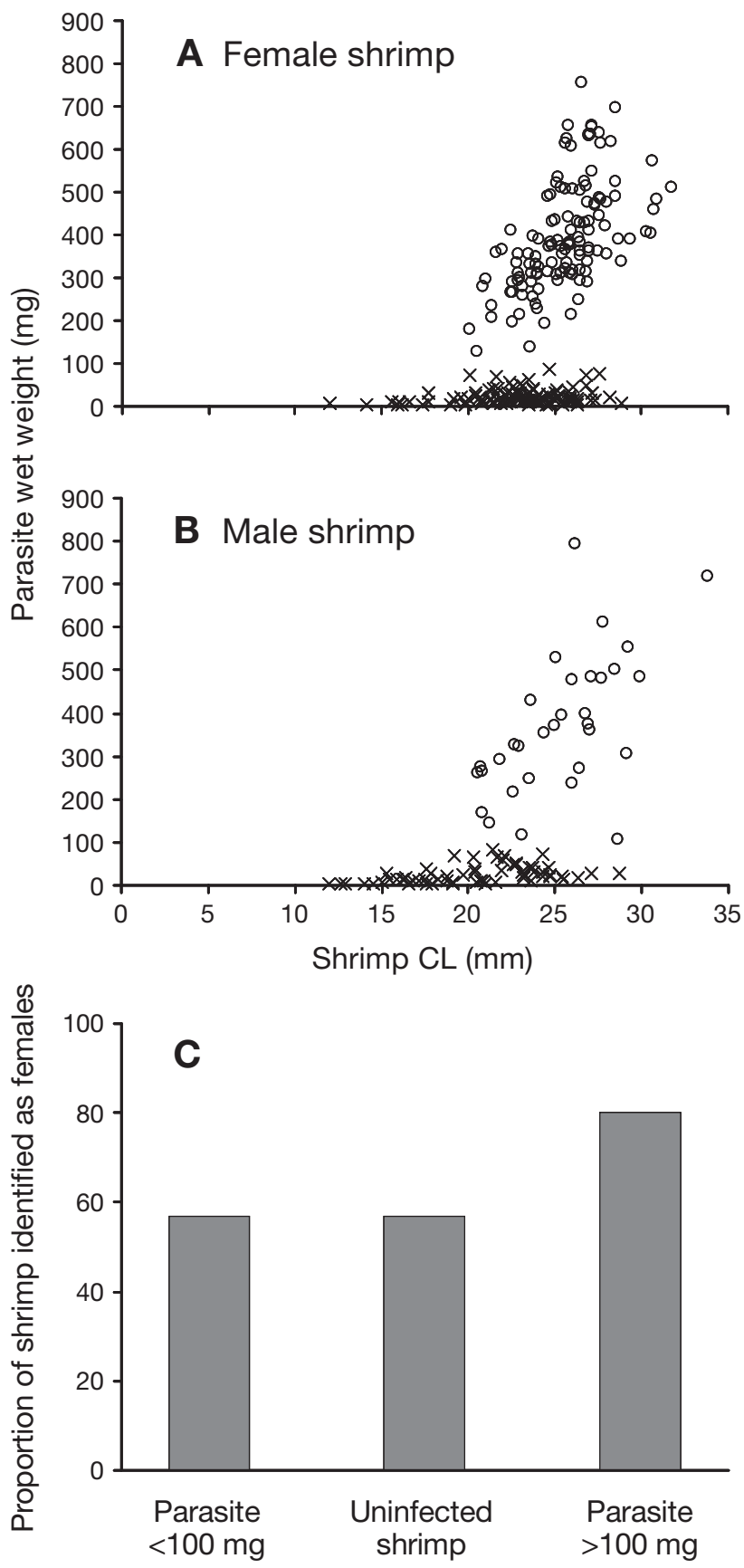

Fig. 4. Orthione griffenis and Upogebia pugettensis. Total wet weight of $O$. griffenis infecting (A) female and (B) male $U$. pugettensis of different sizes. O: parasites $>100 \mathrm{mg} ; \mathrm{X}$ : parasites $\leq 100 \mathrm{mg}$; these 2 size classes were analyzed separately. (C) Proportion of sampled shrimp identified as female that had parasites $<100 \mathrm{mg}$, were uninfected or had parasites $>100 \mathrm{mg}$. CL: carapace length 
The proportion of male versus female shrimp infected varied greatly depending on the size of the parasite. Sixty-two male and 81 female shrimp were infected by female parasites $<100 \mathrm{mg}$. Thus $57 \%$ of the shrimp infected by parasites <100 mg were female. This exactly mirrors the observed sex ratio of uninfected shrimp: 146 males and 194 females, or 57\% female (Fig. 4C). However, only 32 male shrimp were infected by large female parasites (>100 mg), while 125 females were infected by large female parasites. Thus $80 \%$ of the shrimp infected by parasites $>100 \mathrm{mg}$ were identified as female (Fig. 4C).

\section{Simulation models}

Three patterns are important when comparing the observed and predicted distributions. First, parasite prevalence in female shrimp started out relatively low in shrimp from 10 to $15 \mathrm{~mm} \mathrm{CL}(14 \%)$ and then increased monotonically to $85 \%$ prevalence in the largest females (Fig. 2A). Second, parasite prevalence increased with male shrimp size, but saturated at around $50 \%$ for male shrimp $>20 \mathrm{~mm} \mathrm{CL}$ (Fig. 2A). Third, females made up approximately half of the shrimp $<20 \mathrm{~mm} \mathrm{CL}$, and then became increasingly abundant until they comprised $>80 \%$ of shrimp in the largest size classes. These 3 patterns were reproduced with varying success by the mechanisms examined in each of the different models. The ability of each model to reproduce observed trends can be seen by comparing Fig. 2A to each of Fig. 2B-G as described below.

Each of the 6 models reproduced the first observed trend of monotonically increasing parasite prevalence from $<15 \%$ in small female shrimp to $>85 \%$ in large female shrimp (Fig. 2B-G). Each of these models assumed that infection rate was proportional to the size-specific pumping rates of shrimp, as described above and in Table 1 . In contrast, a preliminary model (data not shown) in which infection rate was constant across shrimp size did not accurately recreate this pattern, regardless of the infection rate used. At high constant infection rates ( $>25 \%$ per year), the prevalence in small shrimp was overestimated, whereas at low constant infection rates (<25\% per year), prevalence in large shrimp was underestimated. Thus for female shrimp, the probability of infection increases with shrimp size and appears to be proportional to the size-specific pumping rate of water through the shrimp burrow.

The second trend of increasing infection with size of male shrimp, but maxing around $50 \%$ for shrimp $>20 \mathrm{~mm}$, was reproduced to varying degrees by several of the models. The trend was not reproduced by the null model that lacked any of the mechanisms
(Model 1, Fig. 2B). The only mechanism that was not able to reproduce this trend in any way was background mortality of male shrimp (Model 2, Fig. 2C). This trend was partially reproduced by higher infection-induced mortality of male shrimp (Model 3, Fig. 2D); however, even at $90 \%$ mortality of infected males, the difference in parasite prevalence for large male and female shrimp was only slight. Higher infection rate in female shrimp produced lower prevalence in males of all sizes, rather than in just large males (Model 4, Fig. 2E). Two mechanisms were capable of accurately reproducing this trend. Parasite mortality in male hosts reproduced the trend when mortality was $\geq 70 \%$ per year, but the trend was much weaker as parasite mortality rate decreased (Model 4, Fig. 2F). Feminization of male hosts also reproduced this trend (Model 6, Fig. 2G). When feminization was constant, regardless of parasite size, the observed pattern was qualitatively reproduced, though prevalence in male shrimp in the 20-25 mm CL size class was underestimated. Only when feminization increased with parasite size (i.e. with the time since infection) was the observed pattern accurately replicated. Sensitivity analysis further indicated that the reproduction of this trend broke down when feminization occurred in immature male shrimp (<20 mm CL).

The third trend of a fairly even mix of male and female small shrimp, but increasingly more female shrimp as size increased, was not reproduced by the null model (Model 1, Fig. 2B), by higher infection rate of females (Model 4, Fig. 2E) or by parasite mortality in male hosts (Model 5, Fig. 2F). This trend was weakly reproduced by higher infection-induced mortality of male shrimp (Model 3, Fig. 2D) but, as with the previous trend, even at $90 \%$ mortality of infected hosts, the trend was only weakly reproduced. This trend was also reproduced quite well by 2 mechanisms. Higher background mortality of male shrimp (Model 2, Fig. 2C) reproduced this trend fairly accurately as long as mortality in males was $\geq 15 \%$ higher than in females. Feminization of infected male shrimp also reproduced this trend, but again the pattern was accurately replicated quantitatively only when the probability of feminization increased with parasite size in mature shrimp (Model 6, Fig. 2G).

\section{DISCUSSION}

The general pattern of parasite prevalence observed in 2001 was similar to that observed by Smith et al. (2008) - increasing prevalence with the size of shrimp hosts, and higher prevalence among female than male shrimp (Fig. 2) - despite the difference in methods used for sexing shrimp (Smith et al. 2008, gonopores 
and pleopods; present study, pleopods only). However, there was a general increase at Site 1 between sampling in 2001 (48\% of male and $58 \%$ of female shrimp infected, present study) and 2005 (57\% of male and $80 \%$ of female shrimp infected, Smith et al. 2008). It therefore appears that the prevalence of Orthione griffenis is increasing at this site. This conclusion is not an artifact of differences in shrimp size distribution between 2001 and 2005. Since prevalence is higher in larger shrimp, we may expect higher prevalence in 2005 if there were more large shrimp in the population in 2005 than in 2001. However, the opposite was true: the shrimp size frequency distribution shifted towards smaller individuals in 2005 relative to 2001 (data not shown). Additionally, while there were no significant differences in prevalence between sites, there did appear to be a moderate inverse correlation between prevalence and distance from the mouth of the estuary (Fig. 1), and there was a strong inverse relationship between prevalence and intertidal height, though this relationship comes from only a single, unreplicated transect (Fig. 3A).

Also consistent with the previous study, parasite size generally increased with shrimp size (Fig. 4), though the relationship observed was much stronger than that reported by Smith et al. (2008), potentially reflecting the larger sample size used for the analysis in the present study ( $\mathrm{n}=21$, Smith et al. 2008; $\mathrm{n}=324$, present study). This pattern suggests that parasites frequently infected smaller shrimp and then remained with the shrimp throughout subsequent molts, growing with their host. The fact that some large shrimp were host to relatively small parasites also suggests that parasites are capable of infecting larger shrimp as well. The increasing prevalence of parasites at lower tidal heights (Fig. 3), together with results of the model simulations, suggests that the probability of infection increases with increasing exposure to parasite-laden water, and that this exposure can increase via an increase in both the time that water overlies the burrow (i.e. lower height in the intertidal) and the amount of water passed through the burrow (i.e. via size-specific pumping rates of shrimp).

Results of model simulations suggest that one of 2 scenarios is producing the observed trends in parasite prevalence and shrimp sex ratio shown in Fig. 2A. Feminization of mature male hosts, with the probability of feminization increasing with parasite size, is capable of producing all 3 trends simultaneously (Fig. 2G). No other mechanism was capable of singlehandedly reproducing all of these trends. However, the observed trends may alternatively be produced by a combination of mechanisms. The most likely candidates based on model simulations are higher background mortality of male than of female shrimp com- bined with $>70 \%$ annual mortality of parasites in male hosts only. But which of these 2 alternative scenarios is most likely? This question may be answered most effectively by applying these 2 alternative scenarios (that both explain the patterns in parasite prevalence with shrimp size and the female:male sex ratio for all data combined) to a more restrictive set of patterns specifically, those that occur across tidal heights.

Three patterns are evident across the intertidal heights examined here: (1) a monotonic decrease in parasite prevalence for male shrimp with tidal height (Fig. 3A); (2) a fairly constant prevalence for female shrimp throughout most of the intertidal, but which drops off sharply at the highest elevation examined (Fig. 3A); and (3) a unimodal shift in shrimp sex ratio, with a mid-intertidal minimum in males. It should be noted that although these 3 patterns were strongly present in the single transect across tidal heights reported here, additional data are needed to confirm these trends. I first examine the ability of feminization of infected male hosts to explain each of these 3 patterns, and then I examine whether these patterns could be produced by a combination of high background mortality of male shrimp and parasite mortality in male hosts.

\section{Feminization of infected male hosts}

Sex characteristics in crustaceans are determined by hormone production in the androgenic gland of males (Chang \& Sagi 2008). Androgenic gland hormone $(\mathrm{ADH})$ is required for development and maintenance of male characteristics (Nagamine et al. 1980). Hormone production in turn is nutrition-dependent (Cuzon et al. 2008). Thus mature status and reproductive output in organisms are generally only achieved once basal metabolic demands are met (Karasov \& Martínez del Rio 2007). Parasites frequently alter host nutrition and energy budgets by decreasing energy intake through altering host behavior (e.g. Levri 1999), directly utilizing host food and/or energy reserves (e.g. Walkey \& Meakins 1970), or by altering food metabolism by the host (e.g. Munger \& Karasov 1989). If Orthione griffenis alters shrimp energy budgets, e.g. by consuming their blood as it passes through the gills or imposing oxygen stress by obstructing the gills (thus altering metabolic rate), then this may alter hormone production sufficiently to feminize males.

Next, we must make 2 ecologically reasonable assumptions. First, the risk of infection for male and female shrimp is equivalent and increases with the amount of time exposed to parasite-laden water, and therefore is inversely correlated with tidal height (Fig. 3A). Second, metabolic costs incurred by the host 
because of infection can be met by increasing food intake, and food intake for these suspension feeders is inversely correlated with tidal height.

Based on the common effects of parasites on host physiology and the assumptions given in the preceding paragraphs, we may hypothesize that the trends shown in Fig. 3 could result from the interaction of infection risk and feminization of males as follows. The decrease in the number of males relative to females in the mid-intertidal may reflect not an actual skewed sex ratio, but a perceived skew due to feminization of males so that some males are misidentified as females. With increasing tidal height, reduced submergence time restricts foraging and makes males less capable of meeting extra metabolic costs associated with infection. They therefore become feminized with increasing frequency as tidal height increases. Decreasing parasite prevalence with tidal height (Fig. 3A) likely represents similarly decreasing prevalence for both males and females. Thus in the lowest intertidal sites, males become infected, but their energy intake is sufficient that they can cope with the increased metabolic demands and so are not feminized. As tidal height increases, infection rates decrease for males and females, and infected males increasingly become feminized, supplementing the numbers of apparent infected females and making it appear that infection rates remain constant with tidal height for females.

Settlement of parasites during flow tides will decrease the abundance of parasites in the water. Shrimp found at higher intertidal locations may therefore experience lower parasite abundance in filtered water than shrimp lower down in the intertidal. Thus parasite abundance may interact with pumping time to create differences in prevalence with tidal height.

\section{High background male shrimp mortality combined with mortality of parasites in male hosts}

Inventing an explanation to connect background male shrimp mortality and parasite mortality in male shrimp with the patterns across tidal heights is much less straightforward. Decreasing parasite prevalence in male shrimp with tidal height but constant prevalence in female shrimp (Fig. 3A) could result if submergence time in fact has no effect on infection rate and if parasite mortality in male hosts is exacerbated by tidal height. However, no explanation is apparent for why higher background mortality of male than female shrimp would cause a mid-elevation maximum in the female:male shrimp sex ratio (Fig. 3B).

Results of model simulations, field sampling throughout the Yaquina Bay estuary, and across tidal heights are all therefore consistent with feminization of male hosts by parasites. If feminization is occurring, the separate relationships between parasite and host size for parasites larger and smaller than $100 \mathrm{mg}$ (Fig. 4), together with the shift to greater prevalence in female hosts only for parasites $>100 \mathrm{mg}$ (Fig. 4C), suggests that feminization is more likely once parasites exceed $100 \mathrm{mg}$, likely because larger parasites impose a larger burden on their hosts (Smith et al. 2008). This is also consistent with the much greater proportion of shrimp identified as female that were infected with large parasites, while male and female shrimp infected with small parasites were similar in frequency to the uninfected female:male shrimp frequency (Fig. 4C).

Based on the above explanation, I propose the following testable hypotheses that, if addressed, would greatly contribute to our understanding of the interaction between Upogebia pugettensis and Orthione griffenis:

(1) The risk of infection for U. pugettensis increases with the amount of water pumped through their burrow, which is a function of intertidal location and shrimp size.

(2) Shrimp mortality is not influenced by infection.

(3) Male shrimp may be feminized by infection when they reach maturity, and the probability of feminization increases with the length of time since infection (i.e. with parasite size) and with increasing tidal height (i.e. with the decreasing proportion of time that shrimp can feed and thus meet metabolic demands).

(4) Feminization likely does not occur before the parasite reaches $>100 \mathrm{mg}$.

(5) If these hypothesized impacts of $O$. griffenis on $U$. pugettensis reproduction are accurate, we may expect that $U$. pugettensis will only be reproductively capable in high intertidal regions where infection risk is minimized due to frequent aerial exposure, or in the low intertidal/subtidal regions where infection risk is high, but tides allow for frequent host foraging that provides sufficient energy intake to offset increased metabolic demands.

Testing these hypotheses should improve our understanding of parasite-host interactions and the effects of invasive parasites on novel host population dynamics in general, infection mode and implications of infection in this system in particular, and may elucidate whether invasion by this new parasite is playing an important role in the decline of an important ecosystem engineer along the Pacific coast of North America.

Acknowledgements. This work was supported by the University of South Carolina. Thanks to M. Griffen for assistance in creating Fig. 1. Thanks to anonymous reviewers who greatly improved the manuscript. 


\section{LITERATURE CITED}

Anagnostakis SL (1987) Chestnut blight: the classical problem of an introduced pathogen. Mycologia 79:23-37

Anderson RM, May RM (1978) Regulation and stability of host-parasite population interactions. 1. Regulatory processes. J Anim Ecol 47:219-247

Beck JT (1980) Effects of an isopod castrator, Probopyrus pandalicola, on the sex characters of one of its caridean shrimp hosts, Palaemonetes paludosus. Biol Bull 158: $1-15$

Brenchley GA (1981) Disturbance and community structure: an experimental study of bioturbation in marine softbottom environments. J Mar Res 39:767-790

Brown GP, Brooks RJ, Siddall ME, Desser SS (1994) Parasites and reproductive output in the snapping turtle, Chelydra serpentina. Copeia 228-231

Chang ES, Sagi A (2008) Male reproductive hormones. In: Mente E (ed) Reproductive biology of crustaceans: case studies of decapod crustaceans. Science Publishers, Enfield, NH, p 299-317

Cuzon G, Gaxiola G, Rosas C (2008) Nutrition in relation to reproduction in crustaceans. In: Mente E (ed) Reproductive biology of crustaceans: case studies of decapod crustaceans. Science Publishers, Enfield, NH, p 319-364

Day D (1981) The doomsday book of animals. Viking, New York

DeWitt TH, D'Andrea AF, Brown CA, Griffen BD, Eldridge PM (2004) Impact of burrowing shrimp populations on nitrogen cycling and water quality in western North American temperate estuaries. In: Tamaki A (ed) Proceedings of the Symposium on Ecology of Large Bioturbators in Tidal Flats and Shallow Sediments: from Individual Behavior to their Role as Ecosystem Engineers. University of Nagasaki, Nagasaki, p 107-118

Dumbauld BR, Chapman J (2008) Could burrowing shrimp host populations with pelagic larval dispersal be controlled by an invading parasite? Benthic Ecology Meeting, Providence, RI

Dumbauld BR, Armstrong DA, Feldman KL (1996) Lifehistory characteristics of two sympatric thalassinidean shrimps, Neotrypaea californiensis and Upogebia pugettensis, with implications for oyster culture. J Crustac Biol 16:689-708

> Dumbauld BR, Brooks KM, Posey MH (2001) Response of an estuarine benthic community to application of the pesticide carbaryl and cultivation of pacific oysters (Crassostrea gigas) in Willapa Bay, Washington. Mar Pollut Bull 42:826-844

Gozlan RE, St-Hilaire S, Feist SW, Martin P, Kent ML (2005) Biodiversity: disease threat to European fish. Nature 435: 1046

Granath WO, Esch GW (1983) Survivorship and parasiteinduced host mortality among mosquitofish in a predatorfree, North Carolina cooling reservoir. Am Midl Nat 110: $314-323$

> Griffen BD, DeWitt TH, Langdon C (2004) Particle removal rates by the mud shrimp Upogebia pugettensis, its burrow, and a commensal clam: effects on estuarine phytoplankton abundance. Mar Ecol Prog Ser 269:223-236

Hudson P (2005) Parasites, diversity, and the ecosystem. In: Thomas F, Renaud F, Guégan JF (eds) Parasitism and ecosystems. Oxford University Press, New York, p 1-12
Ironside JE, Smith JE, Hatcher MJ, Sharpe RG, Rollinson D, Dunn AM (2003) Two species of feminizing microsporidian parasite coexist in populations of Gammarus duebeni. J Evol Biol 16:467-473

Jaenike J, Benway H, Stevens G (1995) Parasite-induced mortality in mycophagous Drosophila. Ecology 76: 383-391

Karasov WH, Martínez del Rio C (2007) Physiological ecology. Princeton University Press, Princeton, NJ

Kuris AM (1974) Trophic interactions: similarity of parasitic castrators to parasitoids. Q Rev Biol 49:129-148

> Levri EP (1999) Parasite-induced change in host behavior of a freshwater snail: Parasitic manipulation or byproduct of infection? Behav Ecol 10:234-241

Markham JC (1985) A review of the bopyrid isopods infesting caridean shrimps in the northwestern Atlantic Ocean, with special reference to those collected during the Hourglass Cruises in the Gulf of Mexico. Mem Hourglass Cruises 8: $1-156$

Markham JC (2004) New species and records of Bopyridae (Crustacea: Isopoda) infesting species of the genus Upogebia (Crustacea: Decapoda: Upogebiidae): the genera Orthione Markham, 1988, and Gyge Cornalia \& Panceri, 1861. Proc Biol Soc Wash 117:186-198

May RM, Anderson RM (1978) Regulation and stability of host-parasite population interactions. 2. Destabilizing processes. J Anim Ecol 47:249-267

Mitchell ER (1984) Damage of sunflower by the southern armyworm (Lepidoptera, Noctuidae). Fla Entomol 67: 273-277

Møller AP (2005) Parasitism and the regulation of host populations. In: Renaud TF, Guégan JF (eds) Parasitism and ecosystems. Oxford University Press, New York, p 43-53

Munger JC, Karasov WH (1989) Sublethal parasites and host energy budgets: tapeworm infection in white-footed mice. Ecology 70:904-921

Nagamine C, Knight AW, Maggenti A, Paxman G (1980) Effects of androgenic gland ablation on male primary and secondary sexual characteristics in the Malaysian prawn, Macrobrachium rosenbergii (de Man) (Decapoda, Palaemonidae), with first evidence of induced feminization in a non-hermaphroditic decapod. Gen Comp Endocrinol 41: 423-441

O'Brien J, Van Wyk PM (1985) Effects of crustacean parasitic castrators (epicaridean isopods and rizocephalan barnacles) on growth of crustacean hosts. In: Wenner AM (ed) Crustacean issues, Vol 3: Factors in adult growth. A. A. Balkema, Rotterdam, p 191-218

> Posey MH, Dumbauld BR, Armstrong DA (1991) Effects of a burrowing mud shrimp, Upogebia pugettensis (Dana), on abundances of macro-infauna. J Exp Mar Biol Ecol 148: 283-294

Saumier MD, Rau ME, Bird DM (1986) The effect of Trichinella pseudospiralis infection on the reproductive success of captive American kestrels (Falco sparverius). Can J Zool 64:2123-2125

> Smith AE, Chapman JW, Dumbauld BR (2008) Population structure and energetics of the bopyrid isopod parasite Orthione griffenis in mud shrimp Upogebia pugettensis. J Crustac Biol 28:228-233

Tucker BW (1930) On the effects of an epicaridean parasite, Gyge branchialis, on Upogebia littoralis. Q J Microsc Sci 74:1-11

Walkey M, Meakins RH (1970) An attempt to balance energy budget of a host-parasite system. J Fish Biol 2:361-372

Submitted: April 24, 2009; Accepted: July 18, 2009

Proofs received from author(s): September 10, 2009 